\title{
Chitosan Composites Synthesized Using Acetic Acid and Tetraethylorthosilicate Respond Differently to Methylene Blue Adsorption
}

\author{
Thomas Y. A. Essel ${ }^{1}$, Albert Koomson ${ }^{1}$, Marie-Pearl O. Seniagya ${ }^{1}$, Grace P. Cobbold ${ }^{1}$, \\ Samuel K. Kwofie 1,3, Bernard O. Asimeng 1, Patrick K. Arthur 2,3, Gordon Awandare 2,3 \\ and Elvis K. Tiburu 1,3,* \\ 1 Department of Biomedical Engineering, University of Ghana, P.O. Box LG 25, Legon, Ghana; \\ tyaessel@st.ug.edu.gh (T.Y.A.E.); albert.koomson@stu.ucc.edu.gh (A.K.); \\ moseniagya@st.ug.edu.gh (M.-P.O.S.); gracecobbold2016@gmail.com (G.P.C.); \\ skwofie2000@gmail.com (S.K.K.); boasimeng@ug.edu.gh (B.O.A.) \\ 2 Department of Biochemistry, Cell and Molecular Biology, University of Ghana, \\ P.O. Box LG 25, Legon, Ghana; parthur14@gmail.com (P.K.A.); gawandare@ug.edu.gh (G.A.) \\ 3 West Africa Center for Cell Biology of Infectious Pathogens (WACCBIP), University of Ghana, \\ P.O. Box LG 25, Legon, Ghana \\ * Correspondence: etiburu@ug.edu.gh; Tel.: +233-559585194
}

Received: 20 February 2018; Accepted: 11 April 2018; Published: 24 April 2018

\begin{abstract}
The sol-gel and cross-linking processes have been used by researchers to synthesize silica-based nanostructures and optimize their size and morphology by changing either the material or the synthesis conditions. However, the influence of the silica nanostructures on the overall physicochemical and mechanistic properties of organic biopolymers such as chitosan has received limited attention. The present study used a one-step synthetic method to obtain chitosan composites to monitor the uptake and release of a basic cationic dye (methylene blue) at two different $\mathrm{pH}$ values. Firstly, the composites were synthesized and characterized by Fourier Transform Infrared Spectroscopy (FTIR) and X-ray Diffraction (XRD) to ascertain their chemical identity. Adsorption studies were conducted using methylene blue and these studies revealed that Acetic Acid-Chitosan (AA-CHI), Tetraethylorthosilicate-Chitosan (TEOS-CHI), Acetic Acid-Tetraethylorthosilicate-Chitosan (AA-TEOS-CHI), and Acetic Acid-Chitosan-Tetraethylorthosilicate (AA-CHI-TEOS) had comparatively lower percentage adsorbances in acidic media after $40 \mathrm{~h}$, with AA-CHI adsorbing most of the methylene blue dye. In contrast, these materials recorded higher percentage adsorbances of methylene blue in the basic media. The release profiles of these composites were fitted with an exponential model. The R-squared values obtained indicated that the AA-CHI at $\mathrm{pH} \sim 2.6$ and AA-TEOS-CHI at $\mathrm{pH} \sim 7.2$ of methylene blue had steady and consistent release profiles. The release mechanisms were analyzed using Korsmeyer-Peppas and Hixson-Crowell models. It was deduced that the release profiles of the majority of the synthesized chitosan beads were influenced by the conformational or surface area changes of the methylene blue. This was justified by the higher correlation coefficient or Pearson's $R$ values $(R \geq 0.5)$ computed from the Hixson-Crowell model. The results from this study showed that two of the novel materials comprising acetic acid-chitosan and a combination of equimolar ratios of acetic acid-TEOS-chitosan could be useful $\mathrm{pH}$-sensitive probes for various biomedical applications, whereas the other materials involving the two-step synthesis could be found useful in environmental remediation of toxic materials.
\end{abstract}

Keywords: TEOS; methylene blue; chitosan; modelling; cross-linking; interpenetrating; XRD; FTIR 


\section{Introduction}

Biopolymers are macromolecules produced by living organisms; these include chitin, gelatin, cellulose, and a plethora of other diverse chemical entities. The properties of macromolecules are usually modified to make them suitable for most in vivo and in vitro studies [1,2]. Chitosan, the deacetylated derivative of chitin, is a linear cationic biopolymer of glucosamine residues, specifically $N$-acetyl-D-glucosamine and $N$-D-glucosamine, linked through $\beta$-(1-4)-glyosidic bonds. Due to its abundance, biocompatibility, and low cost, chitosan has been extensively used either in its natural form or as a derivative with other organic or inorganic molecules in various applications including bioseparation, drug delivery systems, environmental remediation, and imaging [3,4].

However, the high crystallinity, minimum surface area, high molecular weight, excessive swelling, and the degree of acetylation of chitosan impact negatively on its solubility, material forming capacity, biodegradability, and diverse bioactive attributes [5]. In addition, organic-based materials such as chitosan possess reactive functional groups including amines and hydroxyls, which are sites for attachment of other macromolecules and metal ions. For decades, efforts have been targeted at the modification of these biopolymers with suitable molecules for a wide range of applications [6]. For example, chemical cross-linkers such as acetic acid, glutaraldehyde, epichlorohydrin, and tetraethylorthosilicate (TEOS) have been used as alternatives to modify the structures of certain biopolymers including chitosan and, as a result, new functional materials with improved physicochemical properties have been produced [7]. Although these cross-linkers improve the mechanical strength, thermal stability, swelling ability, and $\mathrm{pH}$ sensitivity of the chitosan nanocomposite materials, glutaraldehyde, for example, tends to polymerize upon addition to the reaction mixture leading to loss of adsorption sites, thus diminishing the capacity of the resulting end product to be used in drug uptake and delivery [8]. Besides this, most cross-linkers are toxic and their usage in most biomedical applications is limited [9].

The sol-gel process has been used by researchers to synthesize silica nanostructures and optimize their size and morphology by changing either the materials or synthesis conditions [10-12]. It has been established that a mixture of an inorganic strong acid such as TEOS with a weak organic acid (acetic acid) can produce nanostructures with unique properties [13]. For example, chitosan can be cross-linked with TEOS to form an interpenetrative network (IPN), thus enhancing drug permeation as well as controlled release of food nutrients. Similarly, chitosan, when mixed with acetic acid, enhances gelation as well as drug entrapment. A hybrid polymer derived from siloxane and chitosan has also been obtained by the sol-gel technique using tetraethylorthosilicate (TEOS) as a precursor to immobilize enzymes for studying a wide range of applications including bio-sensing and bio-catalysis [14-16].

However, the influence of the silica nanostructures on the overall physicochemical properties of biopolymers such as chitosan has received limited attention. In most reaction conditions, a two-step reaction scheme is adopted: chitosan is first activated by acetic acid, followed by cross-linking with a suitable molecule $[6,7,10,17]$. The underlying question that the current work seeks to investigate is whether a one-step reaction pathway, using a mixture of equimolar concentrations of precursor molecules such as TEOS and acetic acid, can influence the overall structure and properties of the parent chitosan molecule. The present study therefore reports a one-step synthetic method of using chitosan composites to monitor the uptake and release of methylene blue at two different $\mathrm{pH}$ values, with a combination of equimolar mixture of acetic acid and TEOS. The materials' adsorption and release capacities of methylene blue is compared to the results of similarly synthesized chitosan composites using a two-step method at the acidic and basic conditions. Methylene blue was used as a model cationic dye to monitor the physicochemical properties of the materials because it has been established that anionic and cationic dyes, have differential properties depending on the $\mathrm{pH}$ conditions of the media. This work seeks to propose that the dye adsorptive properties towards the chitosan composites are dependent on $\mathrm{pH}$ conditions [18-20]. 


\section{Materials and Methods}

\subsection{Materials}

All analytical-grade chemicals were purchased from Sigma-Aldrich, St. Louis, MO, USA with the exception of TEOS, which was obtained from Philip Harris Ltd., Birmingham, UK. Chitosan (medium molecular weight $M_{\mathrm{w}}=141 \mathrm{kDa}$, and degree of acetylation DA $=15-25 \%$ ) was used as the parent biomolecule for the formation of the composites. Tetraethylorthosilicate (TEOS, 98\% grade), a strong inorganic acid, and glacial acetic acid, a weak organic acid, were used as a cross-linker and an activator, respectively, to modify the chitosan.

\subsection{Methods}

\subsubsection{Synthesis of Chitosan Beads Using Acetic Acid}

Chitosan beads were synthesized with acetic acid according to methods described in previous publications [21,22] with slight modifications.

\subsubsection{Synthesis of Chitosan Beads Using TEOS}

Chitosan beads were synthesized with TEOS according to the above modified method [6]. Briefly, $2 \mathrm{~g}$ of chitosan was added to $2 \%$ v/v TEOS ( $2 \mathrm{~mL}$ TEOS, $6 \mathrm{~mL} 0.5 \mathrm{M} \mathrm{HCl}$, and $92 \mathrm{~mL}$ deionized water) and the resulting mixture stirred until a uniform solution was obtained. The resulting gel was aspirated with a syringe and added in drops to $250 \mathrm{~mL}$ of $2 \mathrm{M} \mathrm{NaOH}$ solution. The beads formed in the $\mathrm{NaOH}$ solution were stirred at room temperature for $24 \mathrm{~h}$ using a magnetic stirrer. The beads were then filtered with deionized water until a neutral $\mathrm{pH}$ was achieved and then air dried.

\subsubsection{Synthesis of Chitosan Beads Using Double Cross-Linking (Acetic Acid Followed by TEOS)}

Chitosan beads were synthesized with acetic acid followed by TEOS according to the established method [23].

2.2.4. Synthesis of Chitosan Beads Using One-Step Method (Equimolar Concentrations of Acetic Acid and TEOS)

The chitosan beads were produced using the sol-gel method with slight modifications [17]. Briefly, $50 \mathrm{~mL}$ of $2 \% v / v$ acetic acid was added to $50 \mathrm{~mL}$ of $2 \% v / v$ TEOS $(1 \mathrm{~mL}$ TEOS, $3 \mathrm{~mL} 0.5 \mathrm{M} \mathrm{HCl}$, and $46 \mathrm{~mL}$ deionized water). A quantity of $2 \mathrm{~g}$ of chitosan was then added and the mixture was stirred until a uniform solution was obtained. The resulting gel was aspirated and added in drops to $250 \mathrm{~mL}$ of $2 \mathrm{M} \mathrm{NaOH}$ solution. The beads formed in the $\mathrm{NaOH}$ solution were stirred at room temperature for $24 \mathrm{~h}$ using a magnetic stirrer. The beads were then filtered with deionized water until a neutral $\mathrm{pH}$ was reached, and then air dried.

\subsubsection{Sample Characterization}

A PANanalytical Empyrean X-ray Diffractometer, Almelo, The Netherlands with $\mathrm{Cu} \mathrm{K} \alpha$ $(\lambda=1.5406 \AA)$ was used to acquire the XRD patterns for chitosan and its derivatives. The scan rate was $2^{\circ}$ per minute in a range of $5-90^{\circ}$. The FTIR spectra were acquired over the region of $500-4000 \mathrm{~cm}^{-1}$ using a PerkinElmer spectrometer, Waltham, Massachusetts, USA. The FTIR scans were processed using the PerkinElmer Spectrum Version 10.03.09.I.

\subsection{Analysis}

\subsubsection{Point of Zero Charge}

The point of zero charge of each composite was estimated by using an established drift method [24]. Briefly, a fixed amount of each of the synthesized beads was added to $10 \mathrm{~mL}$ of deionized water with 
varying $\mathrm{pH}$ values of $2,4,6,8,10$, and 12 . The samples were left to sit for $48 \mathrm{~h}$ after which $\mathrm{pH}$ readings were taken and a graph of the two $\mathrm{pH}$ values was recorded. The points of intersection of the two $\mathrm{pH}$ readings for each sample were recorded.

\subsubsection{Swelling Ratio}

Fixed amounts of the various synthesized beads were immersed in separate $10 \mathrm{~mL}$ buffers ( $\mathrm{pH} \sim 2.6$ and 7.2) and left overnight. The swelling ratio was calculated using the following equation by Park et al. [6].

$$
\text { Swelling ratio }=\frac{\text { Weight of wet or swelled beads }- \text { Weight of dried beads }}{\text { Weight of dried beads }}
$$

The following equation was used to estimate the $\% \varepsilon$ (percentage porosity) as described by Chatterjee et al. [5]:

$$
\% \varepsilon=\frac{\left(W_{\mathrm{W}}-W_{\mathrm{D}}\right) / \rho_{\mathrm{W}}}{\frac{W_{\mathrm{D}}}{\rho_{\text {Mat }}}+\left(W_{\mathrm{W}}-W_{\mathrm{D}}\right) / \rho_{\mathrm{W}}} \times 100 \%
$$

where $W_{\mathrm{W}}$ is the weight of the wet beads in grams before drying; $W_{\mathrm{D}}$ is the weight of the dry beads in grams; $\rho_{\mathrm{W}}$ is the density of water, $1.0 \mathrm{~g} / \mathrm{mL}$; and $\rho_{\text {Mat }}(\mathrm{g} / \mathrm{mL})$ is the material density of the dry bead.

\subsubsection{Methylene Blue Adsorption and Release Properties of the Composites}

Diluted methylene blue solutions adjusted to $\mathrm{pH} \sim 2.6$ and 7.2 were prepared from $1 \mathrm{~g} / \mathrm{L}$ stock methylene blue solution. Adsorbance values were recorded using a JENWAY, 6705 UV-Vis Spectrophotometer, Stone, Staffordshire, UK, at a wavelength of $661 \mathrm{~nm}$. A quantity of $1.5 \mathrm{~mL}$ of the diluted dye was added separately to $50 \mathrm{mg}$ of chitosan beads. The resulting solution was gently agitated for even dispersion of beads in the dye. The solution was left to stand for 16, 20, 24, or $40 \mathrm{~h}$, after which $1 \mathrm{~mL}$ of the supernatant was used for UV-Vis adsorbance readings. Percentage changes in adsorbances at each time interval were calculated using the formula

$$
\% \text { change in adsorbance (methylene blue) }=\frac{A_{\mathrm{t}}-A_{\mathrm{o}}}{A_{\mathrm{o}}} \times 100
$$

where $A_{\mathrm{o}}$ and $A_{\mathrm{t}}$ are adsorbances at times 0 and $t$, respectively.

The release studies were estimated over 240 min using the adsorbent capacity formula as used by Chatterjee et al. [5]:

$$
q=\frac{\left(C_{\mathrm{o}}-C_{\mathrm{eq}}\right)}{W} \times V
$$

where $q$ is the adsorbent capacity, $\mathrm{mg} / \mathrm{g} ; C_{\mathrm{o}}$ is the initial concentration of methylene blue, $\mathrm{g} / \mathrm{L} ; C_{\mathrm{eq}}$ is the final or equilibrium concentration of methylene blue, $\mathrm{mg} / \mathrm{L} ; V$ is the volume of the experimental solution, $L$; and $W$ is the dry weight of the hydrogel beads, g. An exponential fit was used to analyze the best release profile. Models used to describe the release mechanism were Korsmeyer-Peppas and Hixson-Crowell models [25].

\section{Results}

The functionalization of chitosan was undertaken using two cross-linkers at room temperature, and the reaction scheme is outlined in Table 1. The key difference between AA-CHI-TEOS and AA-TEOS-CHI is that the later was generated using a one-step scheme. 
Table 1. Different reaction schemes for the synthesis of chitosan composites.

\begin{tabular}{cccc}
\hline & Chitosan (CHI) & Acetic acid (AA) & TEOS \\
\hline CHI & $\sqrt{ }$ & & \\
AA-CHI & $\sqrt{ }$ & $\sqrt{ }$ & \\
TEOS-CHI & $\sqrt{ }$ & $\sqrt{ }$ & $\sqrt{ }$ \\
a AA-CHI-TEOS & $\sqrt{ }$ & $\sqrt{ }$ & $\sqrt{ }$ \\
b AA-TEOS-CHI & $\sqrt{ }$ & \\
\hline
\end{tabular}

a AA-CHI-TEOS are beads synthesized by first activating chitosan with acetic acid and cross-linked with tetraethylorthosilicate (TEOS). ${ }^{\mathrm{b}}$ AA-TEOS-CHI are beads which were synthesized with a mixture of equimolar concentrations of both acetic acid (weak organic acid) and TEOS (strong inorganic acid).

In Figure 1, the X-ray diffraction patterns of the chitosan and its synthesized composites from acetic acid and TEOS using the different synthetic routes are displayed. The signature peaks of chitosan (CHI) revealed two unique broad peaks at $2 \theta$ degrees at positions $9.1^{\circ}$ and $20.1^{\circ}$, indicating the presence of chitosan [26-28]. The additional peaks at $2 \theta$ degrees of $44.5,64.9$, and 78.0 are probably residual chitin peaks because of the incomplete deacetylation of the parent chitin. Except for AA-CHI-TEOS, all the other composites have similar XRD patterns. Also, additional peaks appeared at about $2 \theta$ degrees of 32 , as well as the reduction of the background (broad peaks) in the AA-CHI-TEOS pattern, indicating the introduction of a crystalline phase into the sample.

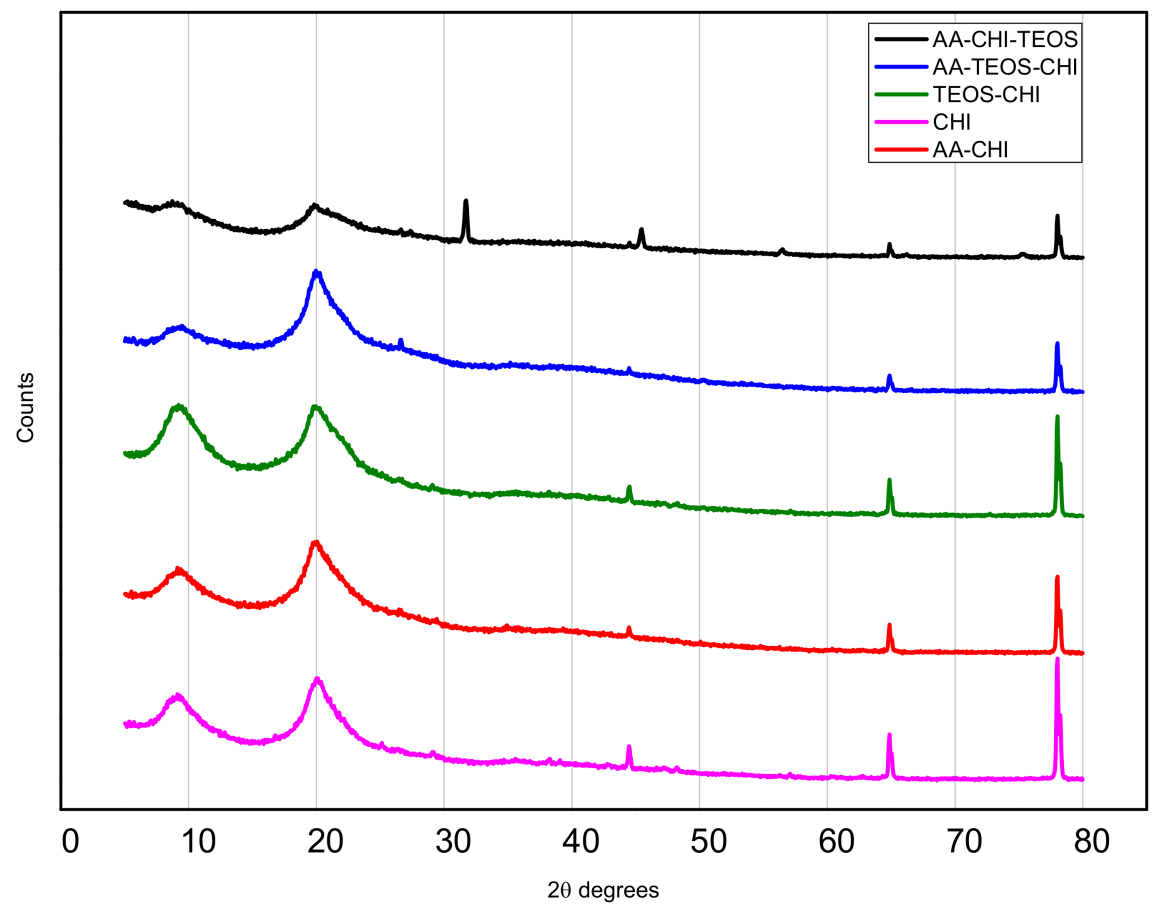

Figure 1. XRD patterns of chitosan and its derivatized composites obtained from acetic acid and TEOS.

The FTIR spectra were obtained within the range of $500-4000 \mathrm{~cm}^{-1}$, but the major fingerprints of chitosan as shown in Figure 2 are between 1000 and $3345 \mathrm{~cm}^{-1}$. Chitosan and its derivatives all showed broad percentage transmittances greater than $3000 \mathrm{~cm}^{-1}$ due to the stretching vibrations of the $\mathrm{O}-\mathrm{H}$ and $\mathrm{N}-\mathrm{H}$ bonds. The relative wavenumbers remained unchanged, but the percentage transmittances of the broad peaks differed based on the treatment of the parent chitosan with the various additives. The doublet peaks at $2921 / 2874 \mathrm{~cm}^{-1}$ are characteristic fingerprints of $\mathrm{C}-\mathrm{H}$ due to symmetric and antisymmetric stretching vibrations. It is also interesting to note that the peaks below $2000 \mathrm{~cm}^{-1}$ have different percentage transmittances with AA-CHI having the highest, indicating that acetic acid treatment of chitosan was very efficient in cross-linking the organic additives with chitosan. Except 
for TEOS-CHI, all the composites showed higher percentage transmittances at wavenumbers below $2000 \mathrm{~cm}^{-1}$ compared with the pure chitosan. When chitosan was treated with only TEOS as in the TEOS-CHI sample, the percentage transmittances of the peaks seemed to diminish. The wavenumbers in the IR spectra of pure chitosan and the derivatized product clearly indicated that the parent chitosan was not chemically different from the product but rather that its percent transmittance was influenced by the organic acids.

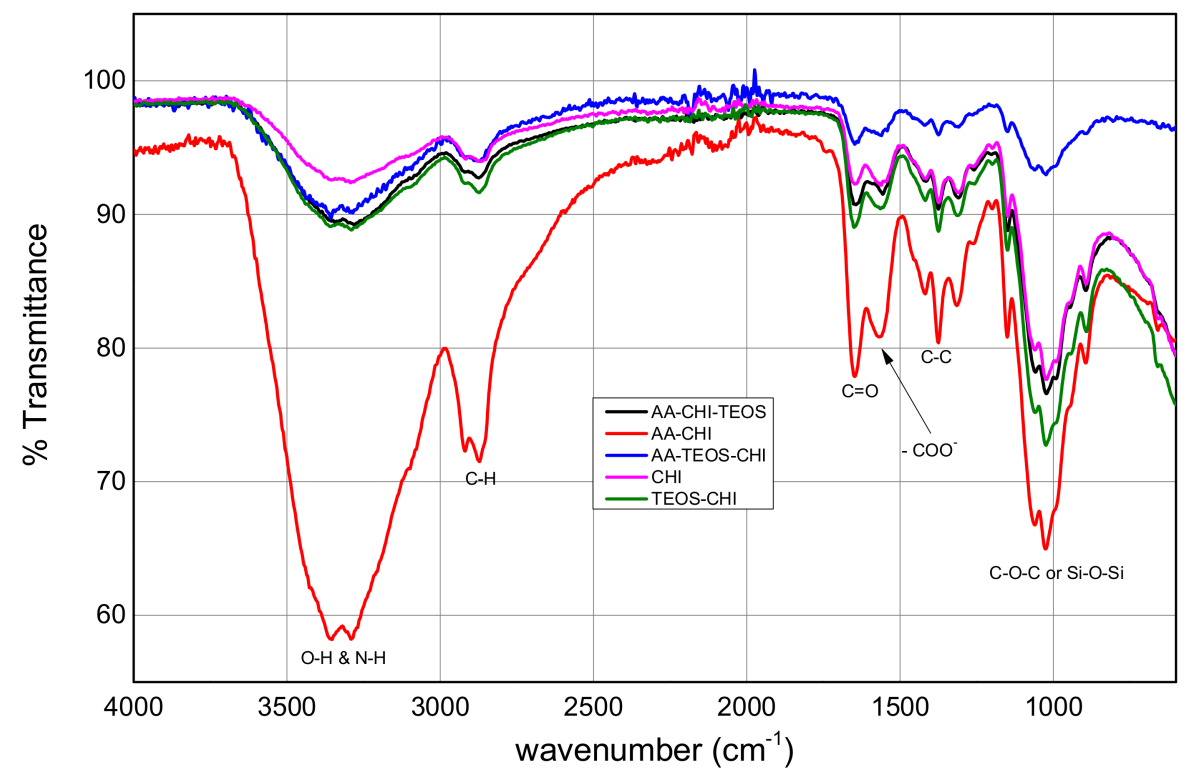

Figure 2. FTIR spectra of pure chitosan and its derivatized composites obtained from acetic acid and TEOS.

The points of zero charge $\left(\mathrm{pH}_{\mathrm{pzc}}\right)$ of each of the materials as well as their water swelling capacities were estimated at different $\mathrm{pH}$ values; the results are displayed in Table 2 . The percentage porosities $(\% \varepsilon)$ of all the synthesized materials are recorded in Table 2 . Almost all the samples at $\mathrm{pH}=2.6$ revealed similar porosities of $86 \%, 87 \%$, and $88 \%$ for AA-CHI, AA-CHI-TEOS, and AA-TEOS-CHI, respectively,

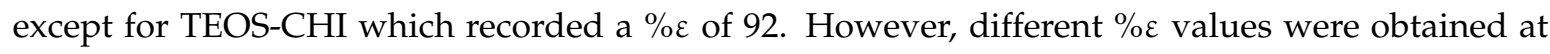
$\mathrm{pH}=7.2$ for AA-CHI (83\%), AA-TEOS-CHI (70\%), AA-TEOS-CHI (77\%), and TEOS-CHI (89\%).

Table 2. Swelling studies conducted at different $\mathrm{pH}$ values. The point of zero charge $\left(\mathrm{pH}_{\mathrm{pzc}}\right)$ of each sample is also indicated.

\begin{tabular}{cccccc}
\hline \multirow{2}{*}{ Sample } & \multicolumn{2}{c}{ Swelling ratio } & \multicolumn{2}{c}{$\%$ Porosity $(\% \varepsilon)$} & \multirow{2}{*}{$\mathbf{p H}_{\mathbf{p z c}}$} \\
\cline { 2 - 5 } & $\mathbf{p H}=\mathbf{2 . 6}$ & $\mathbf{p H}=\mathbf{7 . 2}$ & $\mathbf{p H}=\mathbf{2 . 6}$ & $\mathbf{p H}=\mathbf{7 . 2}$ & \\
\hline AA-CHI & 3.0 & 2.4 & 86 & 83 & 7.6 \\
TEOS-CHI & 4.0 & 2.6 & 92 & 89 & 3.5 \\
a AA-CHI-TEOS & 4.0 & 2.0 & 87 & 77 & 7.1 \\
b AA-TEOS-CHI & 3.0 & 1.0 & 88 & 70 & 7.5 \\
\hline
\end{tabular}

a AA-CHI-TEOS are beads synthesized by first activating chitosan with acetic acid and cross-linked with tetraethylorthosilicate (TEOS). ${ }^{b}$ AA-TEOS-CHI are beads which were synthesized with a mixture of equimolar concentrations of both acetic acid (weak organic acid) and TEOS (strong inorganic acid).

The effect of $\mathrm{pH}$ on the adsorption behavior of methylene blue was investigated in both acidic and basic media in different time frames; the results are as shown in Figures 3 and 4 . It was observed that after $16 \mathrm{~h}$ of adsorption, the trend seemed to favour AA-CHI, with AA-CHI-TEOS exhibiting the least adsorption at $\mathrm{pH}=2.6$, as shown in Figure 3. After $20 \mathrm{~h}$, TEOS-CHI performed best among all 
the materials studied. AA-CHI-TEOS recorded a net negative percentage, indicating water uptake from the methylene blue solution. Similar trends were observed after $24 \mathrm{~h}$ with slight variation in the adsorption behavior between AA-CHI and AA-TEOS-CHI. The pattern seemed to favour TEOS-CHI, with AA-CHI-TEOS exhibiting the least adsorption behavior at $\mathrm{pH}=2.6$, as shown in Figure 3 . However, after $40 \mathrm{~h}$, all the materials, including AA-CHI-TEOS, showed significant amounts of dye adsorption. It was concluded that after $40 \mathrm{~h}$, AA-CHI had a better adsorption capacity among all materials studied at $\mathrm{pH}=2.6$. Unlike at the acidic $\mathrm{pH}$ conditions, however, there was an overall increase in dye adsorption at $\mathrm{pH}=7.2$ with abrupt changes to the adsorption behavior of AA-CHI-TEOS after $40 \mathrm{~h}$, as shown in Figure 4. The pH effect on the methylene blue released was also monitored at different time intervals, as shown in Figures 5 and 6.

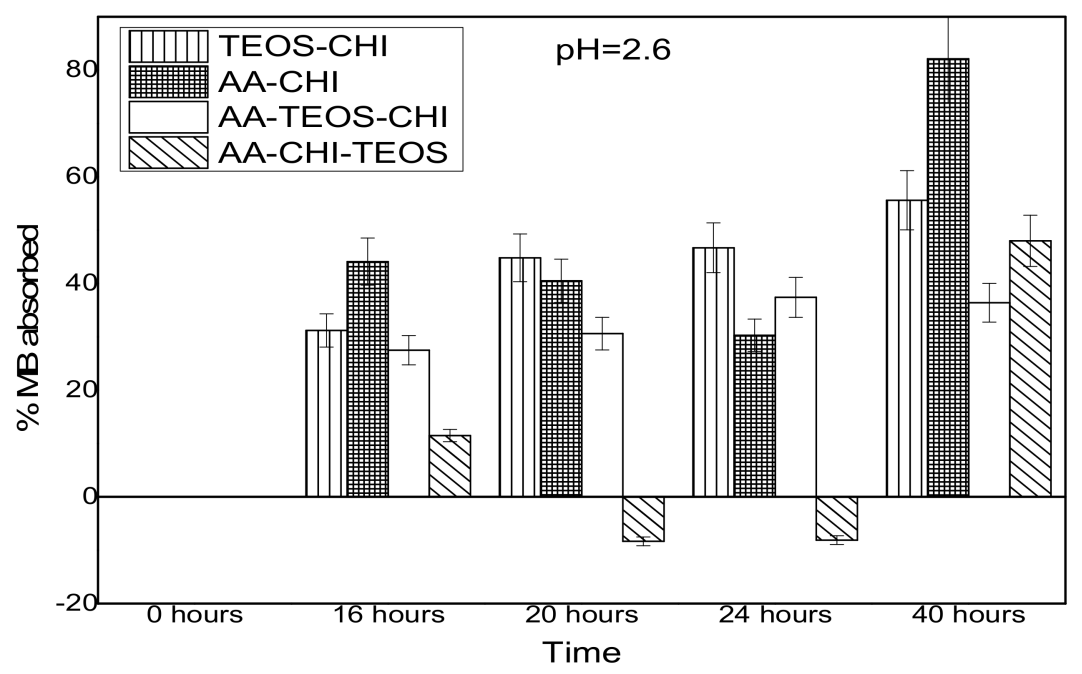

Figure 3. Adsorbance profile of methylene blue at $\mathrm{pH}=2.6$ as a function of time (hours).

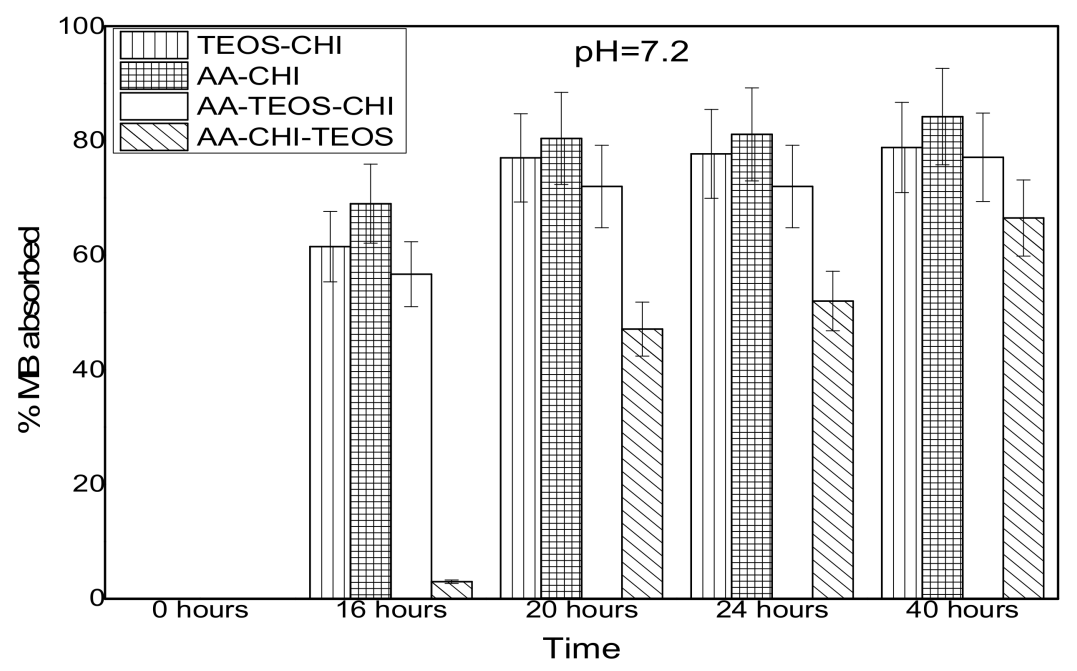

Figure 4. Adsorbance profile of methylene blue at $\mathrm{pH}=7.2$ as a function of time (hours).

The release profile plots of methylene blue over $240 \mathrm{~min}$ are shown in Figures 5 and 6 at $\mathrm{pH}=2.6$ and 7.2, respectively. At $\mathrm{pH}=2.6$, the release profile of AA-CHI follows an exponential order whereas the other materials fluctuate over the same time, as shown in Figure 5. However, at $\mathrm{pH}=7.2$, AA-TEOS-CHI exhibited a unique exponential order as opposed to the other materials as shown in Figure 6. It is interesting to note that AA-CHI, which exhibited progressive exponential order at a lower $\mathrm{pH}$ value in Figure 5, now behaves erratically at high $\mathrm{pH}$ conditions, and vice versa for AA-TEOS-CHI. This could be due to changes in the pore structures either through shrinkage in the 
pore size or the modification of certain functional groups within the pore matrix under different $\mathrm{pH}$ conditions. An exponential curve fitting model was used to extract $R$-squared values for comparison, as shown in Table 3. As observed, AA-CHI performs best, revealing $R^{2}$ values at $\mathrm{pH}=2.6$ and 7.2 of 0.989 and 0.757 , respectively. Similarly, AA-TEOS-CHI also showed reasonable $R^{2}$ values of 0.658 and 0.977 at acidic and basic $\mathrm{pH}$, respectively. Thus, the other functionalized materials could not follow the exponential order profile and were subjected to other mathematical models to explain whether the dye conformational properties could influence the materials' behavior. Nonetheless, as shown in Figure 7 , AA-CHI released the dye efficiently at lower $\mathrm{pH}$, whereas AA-TEOS-CHI performed better at higher $\mathrm{pH}$ with significant degree of accuracy based on the exponential fit model.

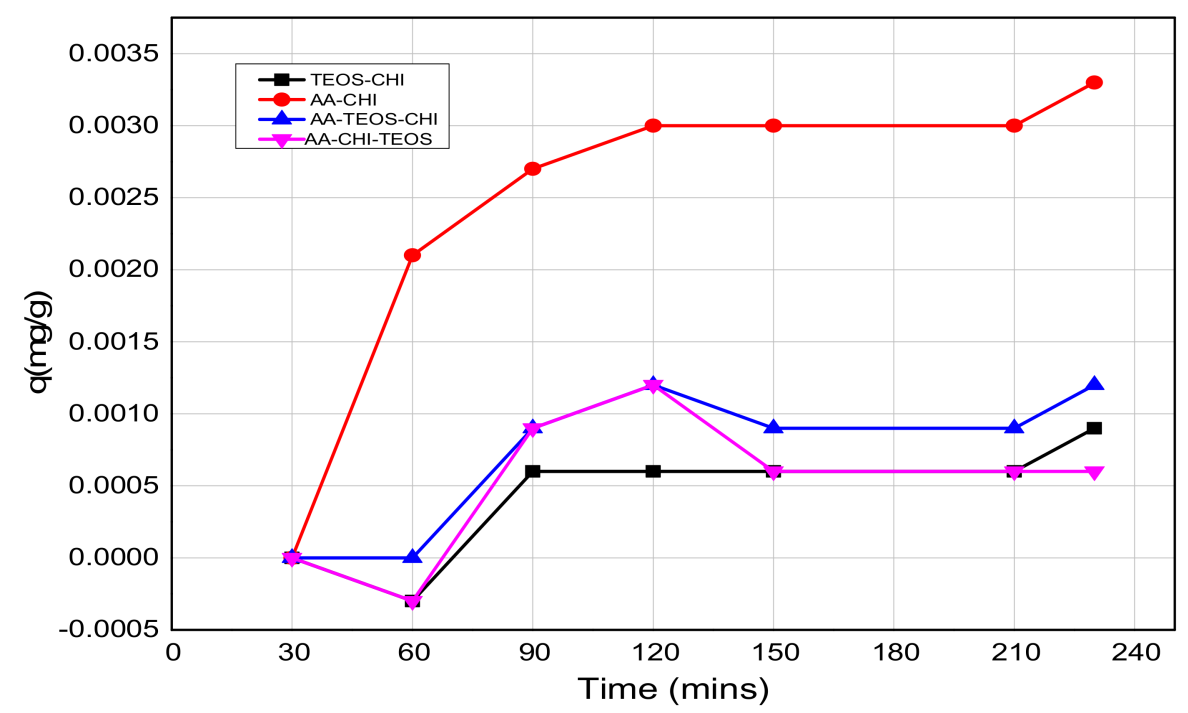

Figure 5. The release profiles of methylene blue at $\mathrm{pH}=2.6$ as a function of time.

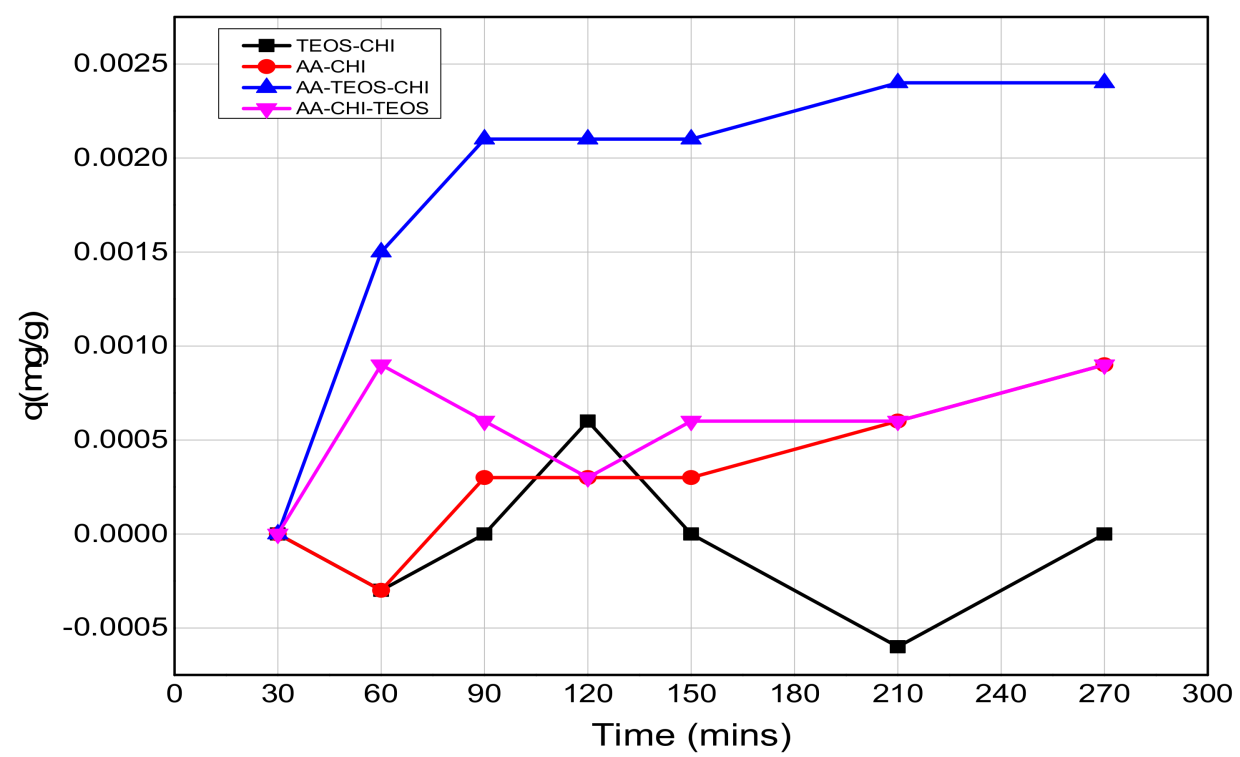

Figure 6. The release profiles of methylene blue at $\mathrm{pH}=7.2$ as a function of time. 


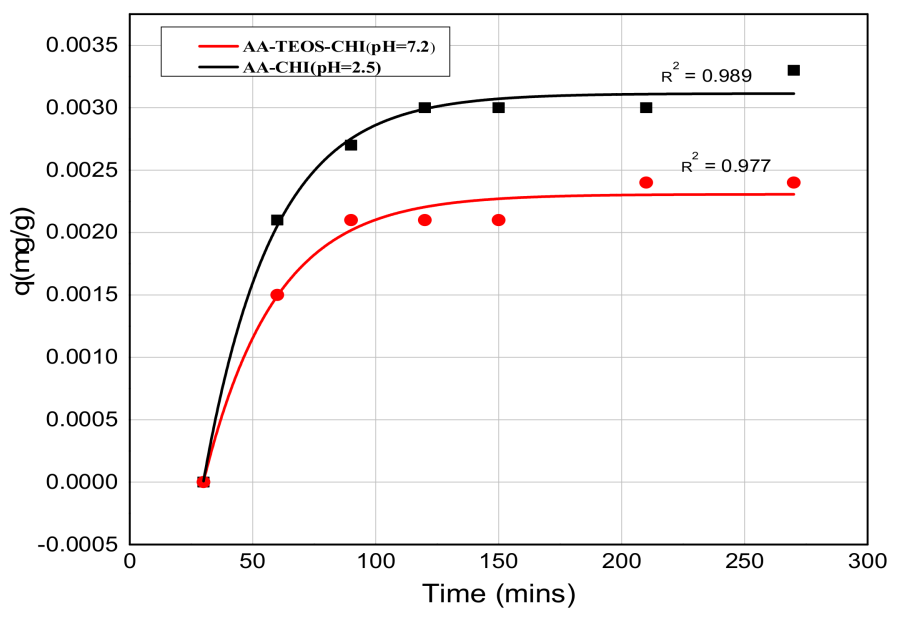

Figure 7. The exponential fit release profile of methylene blue from chitosan composites at two different $\mathrm{pH}$ values. The experimental and fitted values are represented by the scatter plots and the solid lines, respectively.

Table 3. A table of R-squared values obtained from an exponential fit of the release profile.

\begin{tabular}{ccc}
\hline \multirow{2}{*}{ Samples } & \multicolumn{2}{c}{$\mathbf{R}^{\mathbf{2}}$ Values } \\
\cline { 2 - 3 } & $\mathbf{p H}=\mathbf{2 . 6}$ & $\mathbf{p H}=\mathbf{7 . 2}$ \\
\hline AA-CHI & 0.989 & 0.757 \\
\hline TEOS-CHI & 0.539 & -0.5 \\
a AA-CHI-TEOS & 0.156 & 0.380 \\
b AA-TEOS-CHI & 0.658 & 0.977
\end{tabular}

a AA-CHI-TEOS are beads synthesized by first activating chitosan with acetic acid and cross-linking with tetraethylorthosilicate (TEOS). ${ }^{b}$ AA-TEOS-CHI are beads which were synthesized with a mixture of equimolar concentrations of both acetic acid (weak organic acid) and TEOS (strong inorganic acid).

\section{Discussion}

The X-ray diffraction patterns revealed the same positions but different intensities, which probably suggests the introduction of crystalline phase into the chitosan when the biopolymer was treated with the acids. This was especially true for AA-CHI-TEOS, where the background broad peaks had reduced drastically, leading to the appearance of additional peaks. The differences in the FTIR transmittance clearly indicated the modification of the parent chitosan through amide formation and other physicochemical changes caused by the two acids. To facilitate the interpretation of the materials under consideration, parameters such as $\mathrm{pH}_{\mathrm{pzc}}$ and percentage porosity were carefully determined in order to provide the surface charge and porosity information that are crucial determinants of material behavior. All the materials synthesized except for TEOS-CHI were neutral in acidic media based on the point of zero charge $\left(\mathrm{pH}_{\mathrm{pzc}}\right)$ values. In similar acidic conditions, methylene blue also existed as a cationic molecule and, as a result, only simple diffusion of methylene blue would be permissible for the dye uptake into these materials. However, approximately $30-45 \%$ of methylene blue had permeated AA-TEOS-CHI and AA-CHI-TEOS after $40 \mathrm{~h}$, whereas within the same time frame, AA-CHI with comparable $\mathrm{pH}_{\mathrm{pzc}}$ and $\% \varepsilon$ (\% porosity) recorded almost $80 \%$ methylene blue adsorption. These observations underscored the importance of surface charge neutralization and porosity, which are the major determinants of dye adsorption into these materials. As a result, we attributed this behavior to the influence of the silica framework in the adsorption behavior of AA-TEOS-CHI and AA-CHI-TEOS. As previously reported, the swollen state of chitosan within the silica nanostructures at high $\mathrm{pH}$, the insolubility of the chitosan composite, and the barrier created by the silica framework could impact the dye's diffusion into the interpenetration polymer 
pore network of these two materials, causing a significant reduction in methylene blue's uptake [6]. Such physicochemical factors were not available in AA-CHI to impede the simple diffusion of the dye into the activated chitosan. Based on the observations, it was speculated that inherent properties requiring energy for active transport of the methylene blue into AA-CHI-TEOS could be the driving force for the low uptake of the dye. This was especially true for AA-CHI-TEOS where water uptake was the preferred choice for the material as indicated in the negative adsorption profile.

At basic $\mathrm{pH}$, there was rapid response (70-80\%) in methylene blue uptake by all the materials studied after $40 \mathrm{~h}$. It was observed that the percentage porosity of the chitosan composites drastically reduced in basic $\mathrm{pH}$ due to shrinkage of the chitosan within the silica framework, yet dye uptake was significantly higher compared with the values at high $\mathrm{pH}$ (acidic medium). This could be due to the biopolymer shrinkage within the silica framework that might be responsible for the elevated amount of dye uptake at low $\mathrm{pH}$ (basic medium). Again, AA-CHI seems to have the highest adsorption capacity among all the materials because of increased surface area at low $\mathrm{pH}$.

To probe the release kinetics of entrapped methylene blue at the two $\mathrm{pH}$ conditions, the release isotherm model was used to monitor the release of the dye as a function of time in phosphate-buffered saline. The release kinetics of the entrapped methylene blue were evaluated using the Korsmeyer-Peppas $\left(\frac{M_{\mathrm{t}}}{M_{\infty}}=K t^{\mathrm{n}}\right)$ model, where $\frac{M_{\mathrm{t}}}{M_{\infty}}$ is the fraction of the dye released at time $t, K$ is the release rate constant, and $n$ is the release exponent. The $n$ values corresponding to the released mechanism of the dye from the material at different $\mathrm{pH}$ values were determined. The boundary conditions set by the above model to determine the type of release mechanisms of the dye were based on the $n$ values. From our determination, the computed $n$ values from this work concluded that the transport mechanism did not follow the Fickian diffusion mechanism, or other non-Fickian transport such as the Case II transport or Super Case II transport.

Our attention was then directed towards using the Hixson-Crowell Model to evaluate whether conformation changes of the dye could have an influence on the release process. The formula used to evaluate this assertion is given by $C_{\mathrm{o}}{ }^{\frac{1}{3}}-C_{\mathrm{t}}{ }^{\frac{1}{3}}=K_{\mathrm{HC}} t$, where $C_{o}=$ initial amount of drug adsorbed, $C_{\mathrm{t}}=$ amount of drug remaining at time $t$, and $K_{\mathrm{HC}}=$ rate constant. A graph of $\left(C_{\mathrm{o}}{ }^{\frac{1}{3}}-C_{\mathrm{t}}^{\frac{1}{3}}\right)$ was plotted against $t$ for the release profile of each composite synthesized and Pearson's $R$ was recorded based on the linear fit constructed for each release profile. The boundary conditions for this model were that if the absolute value of the correlation coefficient or Pearson's $R$ of the above equation was higher, then the release mechanism was as a result of a change in surface area/conformation of the dye. The Pearson's $R$ for the release profile of each chitosan bead is reported in Table 4 . From the table, it was concluded that change in surface area/conformation of the dye has a significant effect on the respective release profiles of $\mathrm{AA}-\mathrm{CHI}$, AA-TEOS-CHI, and AA-CHI-TEOS at $\mathrm{pH}=2.6$, while in the slightly basic $\mathrm{pH}$, the release of TEOS-CHI, AA-CHI, and AA-TEOS-CHI was also strongly influenced by the change in surface area or conformation of the dye.

Table 4. Evaluation of the release mechanism of methylene blue using Hixson-Crowell model.

\begin{tabular}{|c|c|c|c|c|c|}
\hline \multicolumn{2}{|c|}{ Sample } & \multirow{3}{*}{$\begin{array}{c}\text { TEOS-CHI } \\
-0.18 \\
0.77\end{array}$} & \multirow{2}{*}{$\begin{array}{c}\text { AA-CHI } \\
0.92\end{array}$} & \multirow{2}{*}{$\begin{array}{c}\text { AA-TEOS-CHI } \\
0.76\end{array}$} & \multirow{2}{*}{$\begin{array}{c}\text { AA-CHI-TEOS } \\
0.52\end{array}$} \\
\hline & $\mathrm{pH}=2.6$ & & & & \\
\hline Pear & $\mathrm{pH}=7.2$ & & 0.745 & 0.748 & 0.38 \\
\hline
\end{tabular}

However, it is important to note that the steady rise in the release profile just before the plateau region suggests an asymptotic behavior which is due to the exponential release pattern. In the acidic medium, only AA-CHI revealed a release profile that follows an exponential order but none of the materials' behaviors were able to fit that model. As expected, the adsorption studies in acidic media wherein AA-CHI entrapped most of the dye after $40 \mathrm{~h}$ followed an exponential release curve with an $R^{2}$ value close to 1 . The other composites at the same $\mathrm{pH}$ exhibited a release profile deviant from the exponential model and this is evident from the low $R^{2}$ values. In terms of the release profile in 
basic medium, AA-TEOS-CHI followed an exponential profile reminiscent of what is observed at $\mathrm{pH}=2.6$ for AA-CHI. In terms of the practical applications of the materials synthesized, AA-CHI and AA-TEOS-CHI could be useful for wider biomedical applications including drug entrapment and release due to their steady mechanistic behavior, whereas the other materials could find use in environmental remediation of toxic materials.

\section{Conclusions}

The current study highlights a unique opportunity to utilize a combination of organic and inorganic precursors in either a one-step or two-step reaction mechanism to produce new functional materials that could either be used for targeted drug delivery or for environmental remediation. It has been revealed that two of the materials comprising acetic acid-chitosan and a combination of equimolar ratios of acetic acid-TEOS-chitosan could be useful $\mathrm{pH}$-sensitive probes for various biomedical applications, whereas the other materials from the two-step synthesis could be useful in environmental remediation of toxic materials.

Acknowledgments: We would like to acknowledge support from the West African Centre for Cell Biology of Infectious Pathogens (WACCBIP). The authors also thank the Office of Research, Innovation and Development (ORID) of University of Ghana for funding. We would also like to thank Beatrice Agyapomah at the XRD Facility in University of Ghana as well as John Kutor for the expert advice. We would also like to thank Robert E. Armah-Sekum, Issah Ibrahim and Nadia K. Amoateng for proof reading the manuscript. We also thank the Office of Research, Innovation and Development for supporting this work, Grant \#: UGRF/9/LMG-011(EKT). The work also received support from grants from the Wellcome Trust (WACCBIP DELTAS grant; 107755/Z/15/Z awarded to GAA), and the World Bank Africa Centres of Excellence project (ACE02-WACCBIP) awarded to (GAA).

Author Contributions: Thomas Y. A. Essel, Albert Koomson, Marie-Pearl O. Seniagya and Grace P. Cobbold synthesized the composites and conducted swelling test, dye uptake, release studies and other physicochemical analysis. Samuel K. Kwofie, part of the interpretation and manuscript editing. Bernard O. Asimeng, part of the interpretation and manuscript editing. Patrick K. Arthur did data interpretation and edit the paper. Gordon Awandare contributed analysis tools, laboratory resources and structure of the manuscript. Elvis K. Tiburu conceived the idea, designed the experiments and wrote the manuscript.

Conflicts of Interest: The authors declare no conflict of interest.

\section{References}

1. Algul, D.; Gokce, A.; Onal, A.; Servet, E.; Dogan Ekici, A.I.; Yener, F.G. In vitro release and In vivo biocompatibility studies of biomimetic multilayered alginate-chitosan/beta-TCP scaffold for osteochondral tissue. J. Biomater. Sci. Polym. Ed. 2016, 27, 431-440. [CrossRef] [PubMed]

2. Koc, A.; Finkenzeller, G.; Elcin, A.E.; Stark, G.B.; Elcin, Y.M. Evaluation of adenoviral vascular endothelial growth factor-activated chitosan/hydroxyapatite scaffold for engineering vascularized bone tissue using human osteoblasts: In vitro and in vivo studies. J. Biomater. Appl. 2014, 29, 748-760. [CrossRef] [PubMed]

3. Bernkop-Schnurch, A.; Dunnhaupt, S. Chitosan-based drug delivery systems. Eur. J. Pharm. Biopharm. 2012, 81, 463-469. [CrossRef] [PubMed]

4. Cabral, J.D.; McConnell, M.A.; Fitzpatrick, C.; Mros, S.; Williams, G.; Wormald, P.J.; Moratti, S.C.; Hanton, L.R. Characterization of the in vivo host response to a bi-labeled chitosan-dextran based hydrogel for postsurgical adhesion prevention. J. Biomed. Mater. Res. A 2015, 103, 2611-2620. [CrossRef] [PubMed]

5. Chatterjee, S.; Chatterjee, T.; Lim, S.R.; Woo, S.H. Adsorption of a cationic dye, methylene blue, on to chitosan hydrogel beads generated by anionic surfactant gelation. Environ. Technol. 2011, 32, 1503-1514. [CrossRef] [PubMed]

6. Park, S.B.; You, J.O.; Park, H.Y.; Haam, S.J.; Kim, W.S. A novel pH-sensitive membrane from chitosan-TEOS IPN; preparation and its drug permeation characteristics. Biomaterials 2001, 22, 323-330. [CrossRef]

7. Jothimani, B.; Sureshkumar, S.; Venkatachalapathy, B. Hydrophobic structural modification of chitosan and its impact on nanoparticle synthesis-A physicochemical study. Carbohydr. Polym. 2017, 173, 714-720. [CrossRef] [PubMed] 
8. Cheng, M.; Han, J.; Li, Q.; He, B.; Zha, B.; Wu, J.; Zhou, R.; Ye, T.; Wang, W.; Xu, H.; et al. Synthesis of galactosylated chitosan/5-fluorouracil nanoparticles and its characteristics, in vitro and in vivo release studies. J. Biomed. Mater. Res. B Appl. Biomater. 2012, 100, 2035-2043. [CrossRef] [PubMed]

9. Delval, F.; Crini, G.; Vebrel, J. Removal of organic pollutants from aqueous solutions by adsorbents prepared from an agroalimentary by-product. Bioresour. Technol. 2006, 97, 2173-2181. [CrossRef] [PubMed]

10. Xin, C.; Zhao, N.; Zhan, H.; Xiao, F.; Wei, W.; Sun, Y. Phase transition of silica in the TMB-P123-H ${ }_{2} \mathrm{O}-\mathrm{TEOS}$ quadru-component system: A feasible route to different mesostructured materials. J. Colloid Interface Sci. 2014, 433, 176-182. [CrossRef] [PubMed]

11. Budnyak, T.M.; Pylypchuk, I.V.; Tertykh, V.A.; Yanovska, E.S.; Kolodynska, D. Synthesis and adsorption properties of chitosan-silica nanocomposite prepared by sol-gel method. Nanoscale Res. Lett. 2015, 10, 87. [CrossRef] [PubMed]

12. Toskas, G.; Cherif, C.; Hund, R.D.; Laourine, E.; Mahltig, B.; Fahmi, A.; Heinemann, C.; Hanke, T. Chitosan(PEO)/silica hybrid nanofibers as a potential biomaterial for bone regeneration. Carbohydr. Polym. 2013, 94, 713-722. [CrossRef] [PubMed]

13. Pipattanawarothai, A.; Suksai, C.; Srisook, K.; Trakulsujaritchok, T. Non-cytotoxic hybrid bioscaffolds of chitosan-silica: Sol-gel synthesis, characterization and proposed application. Carbohydr. Polym. 2017, 178, 190-199. [CrossRef] [PubMed]

14. Wang, D.; Liu, W.; Feng, Q.; Dong, C.; Liu, Q.; Duan, L.; Huang, J.; Zhu, W.; Li, Z.; Xiong, J.; et al. Effect of inorganic/organic ratio and chemical coupling on the performance of porous silica/chitosan hybrid scaffolds. Mater. Sci. Eng. C Mater. Biol. Appl. 2017, 70, 969-975. [CrossRef] [PubMed]

15. Matsuhisa, H.; Tsuchiya, M.; Hasebe, Y. Protein and polysaccharide-composite sol-gel silicate film for an interference-free amperometric glucose biosensor. Colloids Surf. B Biointerfaces 2013, 111, 523-529. [CrossRef] [PubMed]

16. Li, F.; Li, J.; Zhang, S. Molecularly imprinted polymer grafted on polysaccharide microsphere surface by the sol-gel process for protein recognition. Talanta 2008, 74, 1247-1255. [CrossRef] [PubMed]

17. Elsagh, A. Synthesis of Silica Nanostructures and Optimization of their Size and Morphology by Use of Changing in Synthesis Conditions. J. Chem. 2011, 9, 659-668. [CrossRef]

18. Gurses, A.; Dogar, C.; Yalcin, M.; Acikyildiz, M.; Bayrak, R.; Karaca, S. The adsorption kinetics of the cationic dye, methylene blue, onto clay. J. Hazard. Mater. 2006, 131, 217-228. [CrossRef] [PubMed]

19. Dos Santos, C.C.; Mouta, R.; Junior, M.C.C.; Santana, S.A.A.; Silva, H.; Bezerra, C.W.B. Chitosan-edible oil based materials as upgraded adsorbents for textile dyes. Carbohydr. Polym. 2018, 180, 182-191. [CrossRef] [PubMed]

20. Ju, H.; Zhou, J.; Cal, C.; Chen, H. The Electrochemical Behaviour of Methylene Blue at a Microcylinder Carbon Fiber Electrode. Electroanalysis 1994, 7, 1165-1169. [CrossRef]

21. Kamari, A.; Ngah, W.S.W.; Liew, L.K. Chitosan and Chemically Modified Beads for acid dyes sorption. J. Environ. Sci. 2009, 21, 296-302.

22. Tiburu, E.K.; Fleischer, H.N.A.; Aidoo, E.O.; Salifu, A.A.; Asimeng, B.O.; Zhou, H. Crystallization of Linde Type A nanomaterials at two Temperatures Exhibit Differential Inhibition of HeLa Cervical Cancer Cells In vitro. J. Biomim. Biomater. Biomed. Eng. 2016, 28, 66-77. [CrossRef]

23. Copello, J.G.; Villanueva, M.E.; Gonzalez, J.A.; Eguez, L.S.; Diaz, L.E. TEOS as an Improved Alternative for Chitosan Beads Cross-Linking: A Comparative Adsorption Study. Appl. Polym. 2014, 131, 41005-41012. [CrossRef]

24. Lopez-Ramon, M.V.; Stoeckli, F.; Moreno-Castilla, C.; Carrasco-Marin, F. On the characterization of acidic and basic surface sites on carbons by various technoques. Carbon 1999, 37, 1215. [CrossRef]

25. Gouda, R.; Baishya, H.; Qing, Z. Application of Mathematical Models in Drug Release Kinetics of Carbidopa and Levodopa ER Tablets. J. Dev. Drugs 2017, 6, 171.

26. Tiburu, E.K.; Salifu, A.A.; Aidoo, E.O.; Fleischer, H.N.A.; Manu, G.; Yaya, A.; Zhou, H.; Efavi, J.K. Formation of Chitosan Nanoparticles Using Deacetylated Chitin Isolated from Freshwater Algae and Locally Synthesized Zeolite A and their Influence on Cancer Cell Growth. J. Nanopart. Res. 2017, 48, 156. [CrossRef] 
27. Argüelles-Monal, W.M.; Lizardi-Mendoza, J.; Fernández-Quiroz, D.; Recillas-Mota, M.T. Montiel-Herrera, M. Chitosan Derivatives: Introducing New Functionalities with a Controlled Molecular Architecture for Innovative Materials. Polymers 2018, 10, 342. [CrossRef]

28. Gohi, B.F.C.A.; Zeng, H.-Y.; Pan, A.D.; Han, J.; Yuan, J. pH Dependence of Chitosan Enzymolysis. Polymers 2017, 9, 174. [CrossRef] 